\title{
16. WARM WINTER, WET SPRING, AND AN EXTREME RESPONSE IN ECOSYSTEM FUNCTIONING ON THE IBERIAN PENINSULA
}

\author{
Sebastian Sippel*, Tarek S. El-Madany*, Mirco Migliavacca, Miguel D. Mahecha, Arnaud Carrara, \\ Milan Flach, Thomas Kaminski, Friederike E. L. Otto, Kirsten Thonicke, \\ Michael Vossbeck, and Markus Reichstein
}

\begin{abstract}
A warm winter 2015/16 followed by a wet spring enabled exceptionally high ecosystem gross primary productivity on the Iberian Peninsula. Climate-ecosystem model simulations show warming winters and increased $\mathrm{CO}_{2}$ availability benefit ecosystem productivity, but no increase in spring precipitation.
\end{abstract}

Introduction. The Iberian Peninsula (IP) experienced unusual meteorological conditions in winter and spring 2015/16 (WS15/16) with a warm winter followed by wet conditions in late winter and spring (Figs. 16.1a-c). The unusual succession of these events coincided with an extremely positive anomaly in vegetation productivity on local and regional scales over the IP with unusually high regional vegetation greenness (Figs. 16.1d-f; a proxy for ecosystem productivity) and high crop yields (JRC MARS Bulletins 2016, https://ec.europa.eu/jrc/en/research -topic/crop-yield-forecasting).

Climatic changes can affect the intensity and frequency of extreme events (Seneviratne et al. 2012), and these changes are widely recognized to impose substantial impacts on terrestrial ecosystems (Reichstein et al. 2013). However, interpreting and quantifying climate-induced ecosystem impacts such as the vegetation productivity on the IP in WS15/16 remains challenging as continuous site-level measurements that span over a decade are generally rare, and even the longest site measurements are only available for the last 25 years (http://fluxnet.fluxdata.org/data /fluxnet2015-dataset/).

AFFILIATIONS: SIPPEL-Max Planck Institute for Biogeochemistry, Jena, Germany, and now at Norwegian Institute of Bioeconomy Research (NIBIO), Ås, Norway;

El-Madany, Migliavacca, Mahecha, Flach, and Reichstein-Max Planck Institute for Biogeochemistry, Jena, Germany; CARRARACEAM, Fundación de la Comunidad Valenciana Centro de Estudios Ambientales del Mediterraneo, Paterna, Spain; KAMINSKI AND VossBeCK-The Inversion Lab, Hamburg, Germany; ОTTOEnvironmental Change Institute, University of Oxford, Oxford, United Kingdom; THONICKE-Potsdam Institute for Climate Impact Research, Potsdam, Germany

DOI:10.1175/BAMS-D-17-0135.I

A supplement to this article is available online (10.1175 /BAMS-D-I7-0135.2)
While long-term climatic changes impose fundamental impacts on terrestrial ecosystems (Parmesan and Yohe 2003; Walther et al. 2002), cause-effect chains under climatic extremes are often highly nonlinear (Frank et al. 2015) and typically include instantaneous and lagged effects (Arnone et al. 2008). Ecosystem responses to climate extremes are specific to the ecosystem type affected (Teuling et al. 2010), depend on nutrient status, ecosystem health, and pre-exposure; and extreme climatic events can lead to little ecosystem responses while moderate events can trigger large responses. Similarly, ecosystem responses can be mitigated or amplified across seasons (Wolf et al. 2016). For example, higher spring carbon uptake due to higher spring temperatures could compensate for carbon losses under drought conditions over the contiguous United States in summer 2012 (Wolf et al. 2016).

To improve our understanding of extreme responses of ecosystem productivity, the concept of compound events is particularly useful. A compound event is a combination, or in our case succession, of events in which the single drivers are not necessarily extreme themselves but lead to an extreme impact (Field et al. 2012; Leonard et al. 2014). A warm winter followed by wet spring in a Mediterranean ecosystem is one example of a compound event in which single drivers (winter temperature and spring precipitation) are not record-breaking extremes themselves, but this favorable combination of meteorological variables can lead to highly positive impacts on ecosystem productivity if other stressors are absent. In particular, for the ecosystem studied, other stressors could include, but are not limited to, short but intense cold spells in

\footnotetext{
${ }^{*}$ S.S. and T.S.E.-M contributed equally to the manuscript.
} 

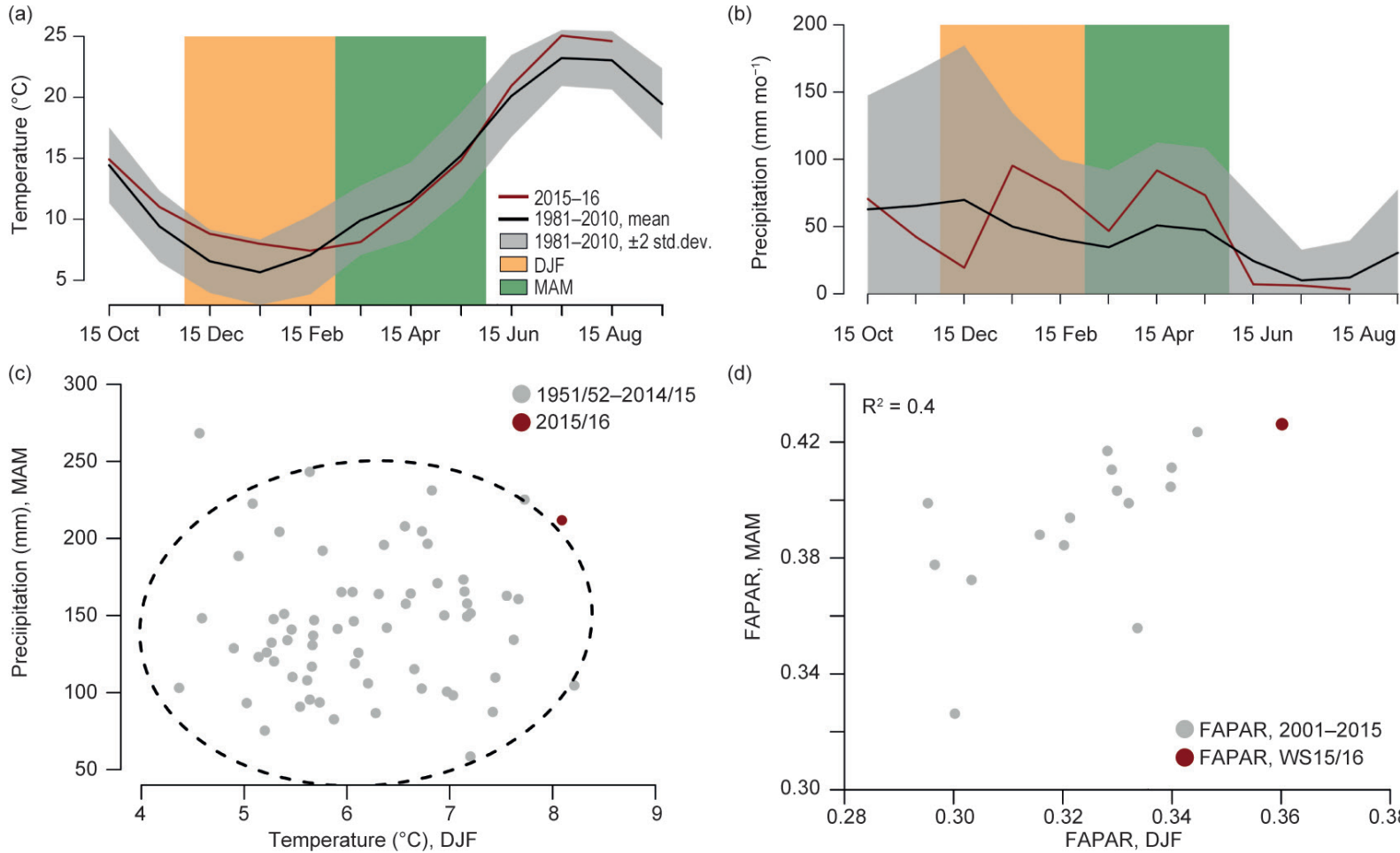

(d)

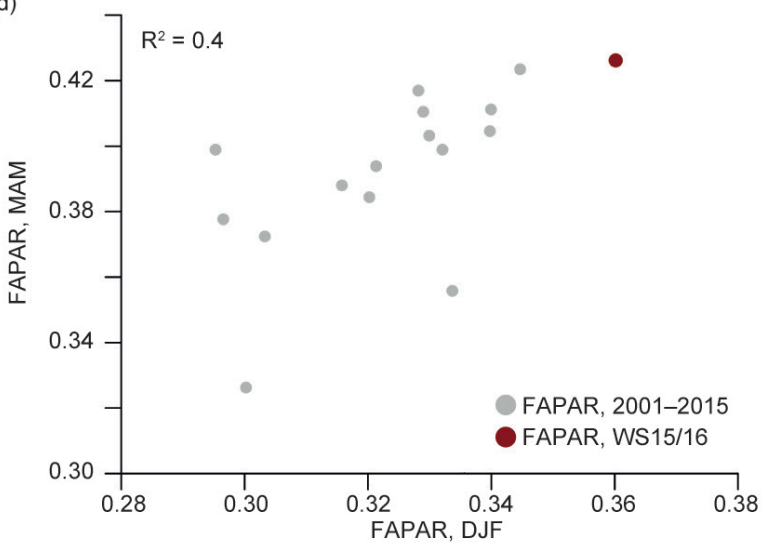

(e)

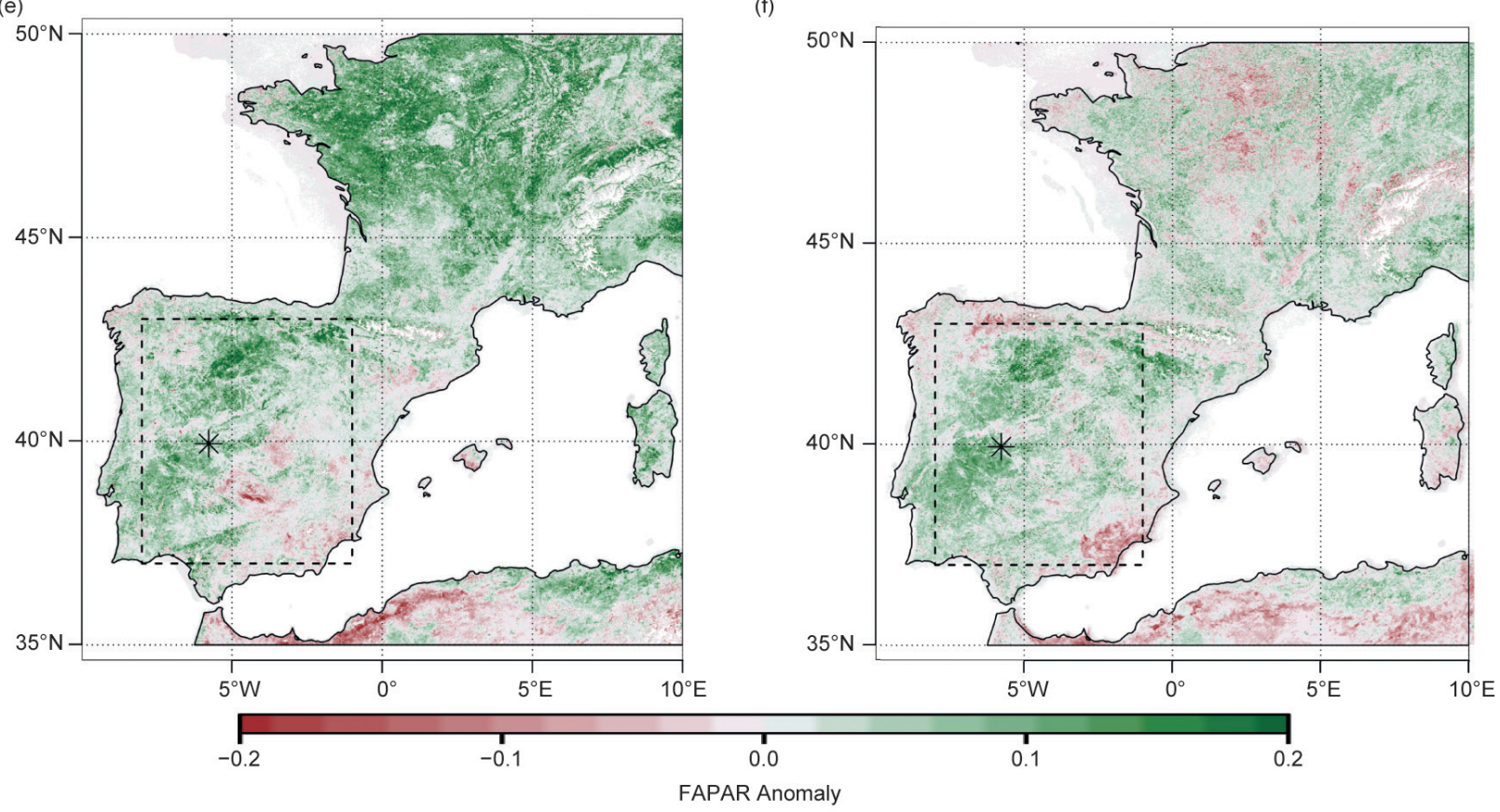

FIG. I6.I. (a),(b) Time series of (a) temperature $\left({ }^{\circ} \mathrm{C}\right)$ and (b) precipitation (mm month-1) over IP in $2015 / 16$ (gray shading indicates $\pm 2 \sigma$ range, w.r.t. $198 \mathrm{I}-2010$ ). (c),(d) Scatter plot of (c) winter temperature ( ${ }^{\circ} \mathrm{C}$ ) and spring precipitation ( $\mathrm{mm}$ month $\left.^{-1}\right)$, and (d) winter and spring fraction of FAPAR. Ellipse denotes quantile of 95\% in multivariate normal distribution (Santos-Fernández 20I2). (e),(f) Map of relative anomaly in FAPAR in (e) winter and (f) spring 2015/16 w.r.t. 200I-16 (black dot indicates study site Majadas del Tietar; rectangle denotes model domain).

winter, moisture stress carried over from previous seasons, fires, pests, or legacy effects thereof.
In this paper, we: 1) analyze the extreme ecosystem productivity anomaly of WS15/16 at the regional scale 
and with site-level measurements, including a process interpretation, and 2) assess, based on an ensemble of process-oriented ecosystem model simulations, how the odds of extremely positive vegetation productivity events [measured in gross primary productivity (GPP) and net ecosystem productivity (NEP)] in winter and spring are changing in response to climate change.

Winter 2015/16 and spring 2016: Meteorological drivers and extreme ecosystem impacts.

a. Regional-scale analysis of vegetation productivity. Strong and persistent anticyclonic conditions prevailed from November to mid-January over the Mediterranean basin, leading to the advection of very mild air into the IP and, in fact, into large parts of western Europe. For example, December 2015 was among the warmest months ever recorded in a range of European countries, such as Spain (2nd; Fig. 16.1a; www.aemet.es /documentos/es/serviciosclimaticos/vigilancia _clima/resumenes_climat/mensuales/2015/res _mens_clim_2015_12.pdf), France(1st; http://actualite .lachainemeteo.com/actualite-meteo/2015-12-26 -06h09/decembre-2015---historiquement-chaud-et -sec-29466.php), and Germany (1st; www.dwd.de /DE/presse/pressemitteilungen/DE/2015/20151230 _deutschlandwetter_dezember_news.html), among others; and combined December and January temperatures exceeded the previous IP area-average record value by $0.72^{\circ} \mathrm{C}$ in the EOBS-dataset (Haylock et al. 2008). In late winter, however, the synoptic situation changed with temperatures returning to near normal, and abundant above-average precipitation over the IP continuing from January through May (Fig. 16.1c). Hence, high winter temperatures were followed by high late winter and spring precipitation, exceeding a bivariate 95th percentile (Fig. 16.1c; see online supplement for details).

Continuously high temperatures during winter enable better functioning of plant enzymes used in the photosynthetic machinery (Sage and Kubien 2007) and prevent plants from damage through cold stress. The availability of water during spring prevents soils from drying out and the plants from experiencing drought stress. The 2015/16 meteorological conditions thus provided the basis for the highest area averaged IP fraction of absorbed photosynthetically active radiation (FAPAR, a proxy for ecosystem productivity observed from space that is related to the state and greenness of vegetation canopies; Gobron et al. 2010) in both winter and spring (Fig. 16.1d), using the Tip-FAPAR dataset (Pinty et al. 2011) in the MODIS era (2001-16); and positive FAPAR anomalies prevailed in both seasons across most of the IP except its southeastern parts (Figs. 16.1e,f).

A correlation analysis of concurrent and lagged meteorological variables and FAPAR at the seasonal time scale shows that IP FAPAR (as a regional-scale ecosystem productivity proxy) is mainly temperaturelimited in winter, which gradually transcends toward water limitation in spring (Table ES16.1). While we focus only on the individual 2015/16 event, in fact out of the four years (i.e., 25\% of the 16-year FAPAR record) that showed the highest December-May IP FAPAR, all four years were among the warmest 30\% of IP winters in the EOBS-dataset, and three out of four among the wettest 30\% of IP springs (and all four within the wettest $35 \%$ of springs on record). Nonetheless, FAPAR in IP ecosystems is also sensitive to precipitation in the previous season both in winter and spring (Table ES16.1), which highlights the role of lagged effects. Hence, the dependence on contemporaneous meteorological conditions should not be mistaken as the sole driver of positive ecosystem productivity events.

b. Site-scale analysis of vegetation productivity. In Spain, 2.16 million hectares of the vegetation used for livestock production consists of a mosaic of at least $20 \%$ oak woodlands plus grass- and shrublands, socalled dehesas. Over a quarter of this vegetation type is located in Extremadura (Campos et al. 2013) in which the study site, Majadas del Tietar $\left(39.9415^{\circ} \mathrm{N}\right.$, $-5.7734^{\circ} \mathrm{E}$ ), is located (Casals et al. 2009).

The site was established in 2003 with meteorological measurements and eddy covariance flux measurements of energy, water vapor, and carbon dioxide, thus a 13-year record is available for analysis.

At site-level, the meteorological variables largely mirrored the regional-scale patterns, that is high temperatures in winter $\left(2.5^{\circ} \mathrm{C}\right.$ above site average in winter) and wet conditions in spring [57 $\mathrm{mm}(\sim 25 \%)$ above site average precipitation in spring]. During the warm winter and wet spring, GPP exceeded the respective seasonal averages by 29 grams of carbon (gC) $\mathrm{m}^{-2}$ month $^{-1}(\sim 45 \%)$ and $43 \mathrm{gC} \mathrm{m}^{-2}$ month $^{-1}$ $(\sim 30 \%)$. In addition, ecosystem respiration (Reco, the release of carbon by the ecosystem), is coupled to temperature and also increased during the warm winter by $29 \mathrm{gC} \mathrm{m}^{-2}$ month $^{-1}$ (70\%) as compared to the average winter. The absence of water stress during the wet spring 2016 also led to increased Reco by $40 \mathrm{gC}$ $\mathrm{m}^{-2}$ month $^{-1}$ (42\%; Fig. ES16.1). Therefore, despite the fact that ecosystem productivity was high in WS15/16 as measured by FAPAR (Figs. 16.1e,f; Pearson correlation between FAPAR and GPP site, $R_{\text {Dec-May }}=0.84$ ), the 

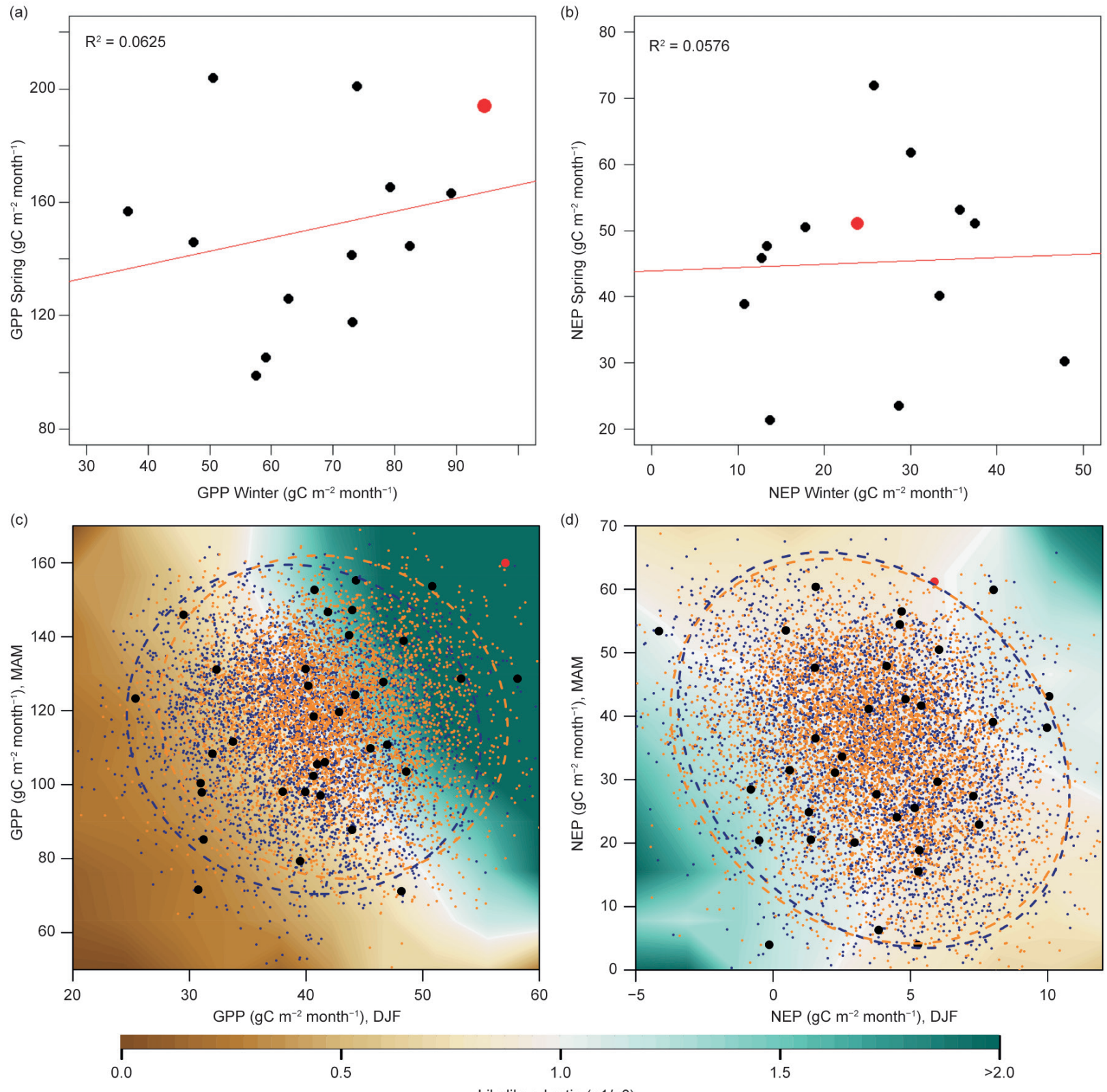

FIG. 16.2. (a) GPP and (b) NEP in winter and spring 2015/16 at Majadas del Tietar w.r.t. earlier years. (c),(d) Area-averaged ensemble ecosystem model simulations over the IP for (c) GPP and (d) NEP for earlier (1986-95, blue dots) and more recent (200I-10, orange dots) period; ellipses indicate bivariate $95 \%$ quantile. Black dots indicate LPJmL simulations driven by ERA-Interim for 1979-2015 (means adjusted); red dot is 2016. Background colors illustrate relative changes in event occurrence probabilities between earlier and more recent period (i.e., $P R=p_{\text {recent }}\left(P_{\text {early }}\right)$ derived from multivariate normal distribution fitted to both model simulation periods individually. Units for GPP and NEP are $\mathrm{gC} \mathrm{m}^{-2}$ month$^{-1}$.

simultaneous increase of GPP and Reco meant that NEP (the net sequestration of carbon) was not unusually high (Fig. 16.2b). This means, that an increase in ecosystem productivity does not necessarily lead to the ecosystem functioning as a larger carbon sink.
How do climatic changes affect regional-scale ecosystem productivity extremes? We provide an estimate of changes in the likelihood of ecosystem productivity extremes such as in 2015/16 based on a processoriented ecosystem model over the time period of 1986-2010. To do so, we evaluate an ensemble of process-oriented ecosystem model simulations over 
the IP (500 members in each year in 1986-2010), using the Lund-Potsdam-Jena managed Land (LPJmL) ecosystem model (Bondeau et al. 2007; Sitch et al. 2003). The simulations are driven by (i) a bias corrected regional climate model ensemble (Massey et al. 2015), and (ii) ERA-Interim reanalysis data (Dee et al. 2011) as a transient simulation reflecting observed meteorology (Pearson correlation between FAPAR and GPP $\mathrm{LPJmL-ERAI}, \mathrm{R}_{\text {Dec-May }}=0.83$ ). Further, the ecosystem model is run in two setups, that is, in standard mode with transient (i.e., observed) $\mathrm{CO}_{2}$ concentrations, and a second setup with $\mathrm{CO}_{2}$ values held constant at 1986 values $\left(\mathrm{CONSTCO}_{2}\right)$ in order to isolate direct $\mathrm{CO}_{2}$ effects on ecosystem functioning. The climate model is driven by observed sea surface temperatures in theweather@home setup (Massey et al. 2015). A detailed methodological description of the HadRM3P-LPJmL ensemble approach is available in Sippel et al. (2017) and is summarized in the online supplement.

Overall, the ecosystem model simulations driven by ERA-Interim indicate that 2015/16 had been an extreme event in regional-scale GPP consistent with site-scale measurements (Fig. 16.2c), and to a lesser degree in NEP (Fig. 16.2d), which differs from site observations that do not indicate anomalous conditions. Contrasting the bivariate distribution of an earlier (1986-95) and a more recent period (2001-10) reveals that the odds for high winter GPP associated with high spring GPP have indeed increased, and the model indicates that the odds for an event similar to 2015/16 have more than doubled (Fig. 16.2c). These changes can be attributed to higher winter temperatures, consistent with anthropogenic climate change, in combination with $\mathrm{CO}_{2}$ fertilization effects in the ecosystem model. Long-term meteorological observations show a strong trend in winter temperatures over the IP (Fig. ES16.2), which is reproduced by the climate model that drives the ecosystem model (both for the 2001-10 vs. 1986-95 decade, but also if the 2001-10 decade is compared to a hypothetical preindustrial 2001-10 ensemble; see Fig. ES16.2 and online supplement text for details). In contrast, there is no significant trend in IP spring precipitation neither in observations nor in the climate model (Fig. ES16.2). Thus increased odds for high spring GPP events that follow high winter GPP events (Fig. 16.2c) cannot be attributed to changes in spring precipitation. Instead, the increased odds in high spring GPP events arise from direct $\mathrm{CO}_{2}$ effects in the ecosystem model, because these changes disappear in the $\mathrm{CONSTCO}_{2}$ scenario (cf. Fig. ES16.3 and Fig. 16.2c). However, crucially, the ecosystem model ensemble simulations also indicate that net ecosystem carbon sequestration, that is after ecosystem respiration is accounted for, has not increased (Fig. 16.2d). This might be due to the fact that higher temperatures are associated with increased Reco (as consistently observed at site scale in Majadas in 2015/16).

Conclusion. Our study shows that the 2015/16 positive GPP anomaly on the Iberian Peninsula, which was enabled by a compound warm winter and wet spring event, is indeed consistent with recent observed climate change, as diagnosed in site and regional scale observations and model simulations. While the increase in winter GPP can be attributed to increasing temperatures, the increase in spring GPP cannot be attributed to changes in spring precipitation, but these changes result from increased $\mathrm{CO}_{2}$ fertilization. However, these warming and $\mathrm{CO}_{2}$-induced effects are largely canceled in terms of net ecosystem carbon sequestration in 2015/16, as carbon uptake and release intensified in tandem, which is consistent with expectations in a changing climate as indicated by the ecosystem model ensemble. This study presents and discusses a novel inquiry into the attribution of ecosystem impacts to extreme climate events and the underlying drivers. However, because it uses only one combination of climate-ecosystem models, and a relatively short observational record, its conclusions should be regarded as contingent on these limitations.

ACKNOWLEDGMENTS. S. S., M. D. M., and M. F. thank the European Space Agency for funding the STSE project CAB-LAB. T. S. E.-M., M. M. and M. R. thank the Alexander von Humboldt Foundation for supporting this research with the Max Planck Research Award to Markus Reichstein. We thank the two reviewers and the editor for their valuable comments and ideas to enhance the quality of this manuscript. 


\section{REFERENCES}

Arnone, J. A., and Coauthors, 2008: Prolonged suppression of ecosystem carbon dioxide uptake after an anomalously warm year. Nature, 455, 383-386, doi:10.1038/nature07296.

Bondeau, A., and Coauthors, 2007: Modelling the role of agriculture for the 20th century global terrestrial carbon balance. Global Change Biol., 13, 679-706, doi: 10.1111/j.1365-2486.2006.01305.x.

Campos, P., L. Huntsinger, J. L. Oviedo, P. F. Starrs, M. Díaz, R. B. Standiford, and G. Montero, Eds., 2013: Mediterranean Oak Woodland Working Landscapes. Landscape Series, Vol. 16, Springer, 508 pp.

Casals, P., C. Gimeno, A. Carrara, L. Lopez-Sangil, and M. J. Sanz, 2009: Soil $\mathrm{CO}_{2}$ efflux and extractable organic carbon fractions under simulated precipitation events in a Mediterranean Dehesa. Soil Biol. Biochem., 41, 1915-1922, doi:10.1016 /j.soilbio.2009.06.015.

Dee, D. P., and Coauthors, 2011: The ERA-Interim reanalysis: configuration and performance of the data assimilation system. Quart. J. Roy. Meteor. Soc., 137, 553-597, doi:10.1002/qj.828.

Field, C. B., and Coauthors, Eds., 2012: Managing the Risks of Extreme Events and Disasters to Advance Climate Change Adaptation. Cambridge University Press, 582 pp. [Available online at www.ipcc -wg2.gov/SREX/images/uploads/SREX-All_FINAL .pdf.]

Frank, D. A., and Coauthors, 2015: Effects of climate extremes on the terrestrial carbon cycle: Concepts, processes and potential future impacts. Global Change Biol., 21, 2861-2880, doi:10.1111/gcb.12916.

Gobron, N., A. Belward, B. Pinty, and W. Knorr, 2010: Monitoring biosphere vegetation 1998-2009. Geophys. Res. Lett., 37, L15402, doi:10.1029/2010GL043870.

Haylock, M. R., N. Hofstra, A. M. G. K. Tank, E. J. Klok, P. D. Jones, and M. New, 2008: A European daily high-resolution gridded data set of surface temperature and precipitation for 1950-2006. J. Geophys. Res., 113, D20119, doi:10.1029/2008JD010201.

Leonard, M., and Coauthors, 2014: A compound event framework for understanding extreme impacts. Wiley Interdiscip. Rev.: Climate Change, 5, 113-128, doi:10.1002/wcc.252.

Massey, N., and Coauthors, 2015: weather@ home-development and validation of a very large ensemble modelling system for probabilistic event attribution. Quart. J. Roy. Meteor. Soc., 141, 1528-1545, doi:10.1002/qj.2455.
Parmesan, C., and G. Yohe, 2003: A globally coherent fingerprint of climate change impacts across natural systems. Nature, 421, 37-42, doi:10.1038 /nature01286.

Pinty, B., and Coauthors, 2011: Exploiting the MODIS albedos with the Two-stream Inversion Package (JRC-TIP): 2. Fractions of transmitted and absorbed fluxes in the vegetation and soil layers. J. Geophys. Res., 116, D09106, doi:10.1029/2010JD015373.

Reichstein, M., and Coauthors, 2013: Climate extremes and the carbon cycle. Nature, 500, 287-295, doi:10.1038/nature12350.

Sage, R. F., and D. S. Kubien, 2007: The temperature response of $\mathrm{C}_{3}$ and $\mathrm{C}_{4}$ photosynthesis. Plant, Cell Environ., 30, 1086-1106, doi:10.1111/j.1365 -3040.2007.01682.x.

Santos-Fernández, E., 2012: Multivariate Statistical Quality Control Using R. SpringerBriefs in Statistics, Vol. 14, Springer, $127 \mathrm{pp}$.

Seneviratne, S. I., and Coauthors, 2012: Changes in climate extremes and their impacts on the natural physical environment. Managing the Risks of Extreme Events and Disasters to Advance Climate Change Adaptation, C. B. Field et al., Eds., Cambridge Univeristy Press, 109-230.

Sippel, S., and Coauthors, 2017: Contrasting and interacting changes in simulated spring and summer carbon cycle extremes in European ecosystems. Environ. Res. Lett., 12, 075006, doi:10.1088/1748-9326/aa7398. Sitch, S., and Coauthors, 2003: Evaluation of ecosystem dynamics, plant geography and terrestrial carbon cycling in the LPJ dynamic global vegetation model. Global Change Biol., 9, 161-185.

Teuling, A. J., and Coauthors, 2010: Contrasting response of European forest and grassland energy exchange to heatwaves. Nat. Geosci., 3, 722-727, doi:10.1038/ngeo950.

Walther, G. R., and Coauthors, 2002: Ecological responses to recent climate change. Nature, 416, 389-395, doi:10.1038/416389a.

Wolf, S., and Coauthors, 2016: Warm spring reduced carbon cycle impact of the 2012 US summer drought. Proc. Natl. Acad. Sci. USA, 113, 5880-5885, doi:10.1073/pnas.1519620113. 